Médico, Doctor en Economía, MSc en Epidemiología, MSc en Bioestadística, MSc en Economía de la Salud Profesor Departamento de Salud Pública, Pontificia Universidad Católica de Chile. Unidad de Evaluación de Tecnologías en Salud, Centro de Investigación Clínica UC ${ }^{\mathrm{a} M D} \mathrm{PhD}$ MSC

Recibido el 13 de junio de 2016, aceptado el 5 julio de 2016.

Correspondencia a: Dr. Manuel Espinoza Departamento de Salud Pública. Diagonal Paraguay 362, Santiago. maespinoza@med.puc.cl

\section{La urgente necesidad de un sistema de Evaluación de Intervenciones en Salud}

\author{
MANUEL ANTONIO ESPINOZA ${ }^{a}$
}

$\mathrm{D}$ esde la reforma de salud 2005, Chile ha introducido importantes elementos en la evaluación de intervenciones y tecnologías en salud, en particular en el contexto de la actualización del plan de beneficios que nació en ese entonces, el Régimen de Garantías Explícitas en Salud (GES) ${ }^{1}$. Estos elementos se centraron en la revisión crítica de la evidencia clínica utilizando los métodos de medicina basada en evidencia, los cuales han sido centrales para (a) la construcción de guías de práctica clínica y (b) para la definición de las canastas de coberturas. Sin embargo, cabe destacar que estos dos componentes de evaluación (guías y canastas) no tienen un correlato perfecto. Si bien todo lo que está en la canasta debiera estar en la guía, lo contrario no ocurre necesariamente.

La definición de estas canastas del GES son por cierto el punto crítico que vincula al trabajo de análisis crítico de evidencia médica con la decisión de cobertura. No obstante,esta información está lejos de ser la única. Además de la evidencia clínica existe una evaluación económica que determina la decisión. Es así que la Ley GES menciona dos tipos de evaluación económica: primero, el estudio de verificación de costos, es decir, la estimación de cuánto es el costo esperado de GES en promedio por beneficiario. Esto es equivalente al impacto presupuestario del plan de beneficios GES, y se hace cada vez que se actualiza el plan con nuevos problemas de salud. Segundo, la ley dice que se debe considerar la costo-efectividad cada vez que sea posible. Sin embargo, desde el inicio del GES, rara vez estas decisiones han contado con la evidencia de costo-efectividad. En consecuencia, desde el lado económico las decisiones de cobertura parecen estar basadas fundamentalmente en elementos financieros (impacto presupuestal) y mucho menos en lo sanitario (costo-efectividad).

Cabe destacar que el GES no es el único plan de beneficios con que cuenta Chile. Además, existen los Programas de Prestaciones Valoradas (PPV) y de Prestaciones Institucionales (PPI) de FONASA y, más recientemente, la Ley Ricarte Soto. En todos estos esquemas de cobertura, la autoridad debe -al menos- revisar evidencia clínica, hacer algun tipo de evaluación económica y tomar una decisión. En consecuencia, la autoridad sanitaria está continuamente debiendo tomar decisiones para la actualización de estos esquemas de cobertura.

Estas decisiones de cobertura en Chile están centralizadas en el Ministerio de Salud y sus entidades dependientes. Para ser más claro, todo el proceso de decisión está centralizado, desde la selección de lo que se va a revisar, pasando por la revisión crítica de la evidencia científica tanto clínica como económica, su valoración y finalmente la decisión propiamente tal. Sin embargo, cabe reconocer que a lo largo del proceso hay participación de algunos actores como expertos clínicos, quienes ayudan en la generación de guías clínicas y las canastas. No obstante, es finalmente la autoridad quien lidera y controla el proceso.

En contraste con lo que ocurre en Chile, la experiencia internacional muestra avances importantes en la implementación de procesos de decisión más sistemáticos, mejor definidos, más trasparentes y más participativos ${ }^{2,3}$. Varias de las razones que motivan estos procesos aplican 
igualmente en Chile. Primero, el desarrollo tecnológico en salud supera con creces las capacidades de financiar estas innovaciones por parte de los sistemas de salud. Segundo, el nivel de tecnicismo requerido para evaluar la evidencia ha llegado a niveles altamente especializados. Además de la medicina basada en evidencia están los métodos de síntesis, evaluación económica, modelamiento matemático y análisis de incertidumbre, que raramente pueden ser ejecutados desde los ministerios por falta de dotación con todas las capacidades especializadas. Esto ha llevado a establecer un modelo colaborativo con centros académicos y/o de investigación y sociedades científicas. Tercero, incluso cuando la evidencia (médica, económica y social) es clara, la valoración e interpretación de esa evidencia por distintos actores puede determinar decisiones opuestas. Por ejemplo, algunos sectores pueden querer privilegiar el financimiento de enfermedades poco frecuentes severas por sobre otras más prevalentes y menos severas. Por esta razón, varios países han incluido procesos que incluyen la deliberación participativa en torno a la información científica y disponen mecanismos de reposición y apelación.

En otro contexto está la demanda social por contar con procesos confiables. Chile enfrenta una grave crisis que ha cuestionado la legitimidad de las decisiones que emanan de cuerpos del estado ${ }^{4}$. No es claro para la mayoría de la ciudadanía hasta qué punto las decisiones están únicamente basadas en el bien social o son determinadas -al menos parcialmente- por factores políticos que atienden a otros objetivos. Es así que el solo argumento de contar con cuerpos técnicos dentro de los ministerios no es garantía de que las decisiones sean las más adecuadas para los ciudadanos. Resta entonces una instancia donde, al menos lo estrictamente técnico, pueda ser revisado por distintos actores y así creíble por la sociedad. Luego, si los objetivos políticos contravienen las recomendaciones científicas, estas decisiones serán materia de escrutinio público.

Sin embargo, a pesar de estos argumentos, los médicos y los profesionales de la salud hemos sido actores poco activos en la crítica sobre cómo se procede actualmente y del marco institucional dispuesto para ésto. Debo aclarar que esta aseveración se dirije al conjunto y no a los profesionales como individuos o grupos de especialistas, quienes sí expresan sus críticas muy proactivamente. Sin embargo, éstas se originan muy frecuentemente en el contexto de los problemas específicos (por ejemplo, gastroenterólogos luchando por cobertura de drogas para hepatitis $\mathrm{C}$ ), pero no como una demanda sistémica que afecta por igual a todas las áreas o especialidades del sector salud.

No es posible que en un país como Chile, los temas de cobertura sanitaria sean abordados desde la presión social y las coyunturas. En un sistema con restricciones presupuestarias, este enfoque beneficia a quienes reclaman y postergan a los grupos minoritarios con menor capacidad de demanda social, a quienes -por lo demás- no se les da ninguna explicación del por qué fueron postergados. Si bien la solución no es fácil, la experiencia internacional muestra que una institucionalidad de Evaluación de Intervenciones en Salud independiente, es una alterativa mucho más justa que lo que hoy tenemos en Chile.

El Ministerio de Salud ha avanzado en dos lineas en los últimos años. Primero, desarrolló una propuesta para la institucionalización de la Evaluación de Tecnologías Sanitarias. Esta propuesta emanó de la Comisión Nacional de Evaluación de Tecnologías en Salud ${ }^{5}$, que sólo incluyó representantes de instituciones dependientes del Ministerio. Resta entonces su divulgación activa, discusión y escrutinio público. Por otro lado, ha creado un Departamento de Evaluación de Tecnologías en Salud, un grupo técnico para responder a las necesidades de la autoridad, algo que por cierto es importante y deseable. Sin embargo, el país requiere algo distinto a lo que el MINSAL está haciendo ahora (y que está muy bien que lo haga); necesita de un sistema independiente y confiable que no sólo responde las prioridades de la autoridad de salud sino al país en su conjunto.

¿Qué ocurre si no avanzamos en implementar este sistema? Primero, los grupos de pacientes seguirán marchando y demandando sus necesidades de manera aislada. Algo similar seguirán haciendo los expertos clínicos, quienes centrados en el cuidado de sus pacientes, también demandarán nuevas intervenciones. La industria de innovación ve que el único camino para vender sus productos es ayudar a los pacientes y médicos a posicionar sus demandas, algo que no nos acomoda como sociedad. Incluso si la industria no hiciera ningún esfuerzo en este sentido, le resta tomar palco hasta que la demanda social sea tal que la autoridad se vea obligada a comprar la innovación al precio que 
le impone la industria, en un impeorable escenario para la negociación de estos precios.

Por otro lado, no existirá tiempo para que la autoridad planifique la priorización sanitaria. La demanda social será tal, que la autoridad estará obligada a tomar decisiones en tiempos muy cortos y con poca evidencia científica, pues no tendrá tiempo para generarla. Las prioridades por cierto estarán determinadas por quienes reclaman y no necesariamente por las necesidades de la población. Luego, si con todas estas restricciones el proceso de revisión de evidencia y decisión fuese público, sería altamente cuestionado por lo insuficiente; por lo tanto, lo más probable es que no sea todo público para evitar mayor descontento social, lo cual nos ubica exactamente donde estamos hoy.

Con todo esto, la implementación de un proceso de estas características no sólo es necesario si no que es urgente. La urgencia radica en que no es un sistema fácil y que probablemente requerirá ajustes en el tiempo, al menos así ha ocurrido en la mayoría de los países que han avanzado en este tema. Sin embargo, están los ingredientes necesarios para empezar. Un elemento fundamental es que en los últimos años las universidades han avanzado significativamente en formar capacidades técnicas. Otro factor esencial es la organización de grupos como asociaciones de pacientes cada vez más empoderados y capaces de participar de estos procesos. Finalmente, quienes hemos estado en la discusión de este tema observamos que todos los sectores sociales y políticos se muestran de acuerdo con estos principios.

En definitiva, la mejor solución al problema planteado es avanzar en una institucionalidad independiente de evaluación de intervenciones en salud, idea que cuenta con bastante sintonía entre los distintos actores sociales. Sin embargo, esta es una iniciativa que debe ser liderada por la autoridad sanitaria. Lamentablemente, no ha puesto este tema dentro de sus prioridades, quizás porque no ha sentido la necesidad desde la sociedad. En base al estilo de hacer política en Chile, resulta esencial que los distintos actores (pacientes, pagadores, prestadores, sociedad en general) hagan una demanda clara de esta necesidad. Sólo resta hacer una invitación abierta a las sociedades médicas y gremios de profesionales de la saluda abordar y entender el alcance que este tema tiene en la práctica profesional actual y el impacto sobre nuestros pacientes. Sólo así se podrán coordinar los esfuerzos para una demanda clara de un proceso justo de decisiones sobre cobertura en salud en Chile.

\section{Referencias}

1. Establece un Regimen de Garantías en Salud, (2004).

2. Banta D, Kristensen FB, Jonsson E. A history of health technology assessment at the European level. International journal of technology assessment in health care. 2009; 25 Suppl 1: 68-73.

3. Chalkidou K, Marten R, Cutler D, Culyer T, Smith R, Teerawattananon $\mathrm{Y}$, et al. Health technology assessment in universal health coverage. Lancet 2013; 382 (9910): e48-9.

4. Micco S. Escándalo político y rol cívico del personal de la salud. Rev Chil Pediatr 2015; 86 (3): 138-41.

5. Comisión Nacional de Evaluación de Tecnologías Sanitarias. Propuesta de un modelo de implementación e institucionalización de la Evaluación de Tecnologías Sanitarias en Chile. Disponible en: http://web.minsal. $\mathrm{cl} /$ sites/default/files/files/InformeFinalPropuestaETESAChile.pdf. Santiago2014. 